\title{
Las estrategias sindicales de las trabajadoras de casa particular en Chile en su lucha contra la precariedad (2010-2014)
}

The union strategies of domestic workers in Chile in its fights against precarity (2010-2014)

Nicolás Ratto*

Resumen. El año 2014 las tres principales organizaciones de trabajadoras de casa particular de Chile consiguieron una importante modificación legal (Ley $\mathrm{N}^{\circ} 20.786$ ) que, al menos formalmente, mejora sus condiciones de empleo y de trabajo, haciendo menos precaria la labor de estas trabajadoras. El presente artículo busca explicar esta victoria de las trabajadoras de casa particular, dados sus bajos poderes estructurales y asociativos. Por medio del análisis de 13 entrevistas en profundidad a trabajadoras sindicalizadas y no sindicalizadas, un grupo focal con socias del sindicato SINTRACAP, revisión de prensa e historia legislativa, y observación participante (2017-2019) se concluye que el SINTRACAP desarrolló tres tipos de estrategias sindicales en el periodo 2010-2014, que le permitieron conseguir la mencionada reforma: (1) establecimiento de alianzas con otras organizaciones y sindicatos del gremio, (2) movilización de la institucionalidad internacional para presionar al Estado chileno y (3) generación de alianzas, intercambios y algunas presiones hacia los actores políticos para que aprueben reformas a su favor. La movilización de estos poderes "externos" le ha permitido a la organización sortear su debilidad y representar eficazmente los intereses del gremio, pero también, la ha hecho descansar en estos poderes externos, evitando el desarrollo de poderes asociativos propios.

Palabras Claves: estrategias sindicales, trabajadoras de casa particular, debilidad estructural, recursos de poder, Ley $\mathrm{N}^{\circ} 20.786$.

\begin{abstract}
In 2014, the three main organizations of domestic workers in Chile achieved an important legal modification (Law No. 20,786) that, at least formally, improves their employment and work conditions, making the labor of these workers less precarious. The present article seeks to explain this victory of domestic workers, given their low structural and associative powers. Through the analysis of 13 in-depth interviews with unionized and non-unionized workers, a focus group with members of the SINTRACAP union, press review and legislative history, and participant observation (2017-2019), it is concluded that SINTRACAP developed three types of strategies unions in the period 2010-2014, which allowed them to achieve the aforementioned reform: (1) establishment of alliances with other organizations and unions of domestic workers, (2) mobilization of international institutions to put pressure on the Chilean State and (3) generation of alliances, exchanges
\end{abstract}

\footnotetext{
* Chileno. Sociólogo y Magíster en Ciencias Sociales por la Universidad de Chile. Investigación financiada por el Consejo Nacional de Ciencia y Tecnología (CONICYT), Programa de Becas Magister Nacional (2017-2018) y por el Fondo de Iniciación a la Investigación de la Dirección de Asuntos Estudiantiles de la Facultad de Ciencias Sociales (FACSO) de la Universidad de Chile. Correo electrónico: nicolas.ratto@ug.uchile.cl
} 
and some pressure on political actors to approve reforms in their favor. The mobilization of these "external" powers has allowed the organization to overcome its weakness and effectively represent the interests of the domestic workers, but also, it has relied on these external powers, avoiding the development of its own associative powers.

Key words: union strategies, domestic workers, structural weakness, power resources, Law No. 20,786

Recibido: 10 enero 2019 Aceptado: 13 abril 2019

\section{Introducción}

El año 2014 las tres principales organizaciones de trabajadoras de casa particular de Chile consiguieron que el parlamento aprobará la Ley N²0.786 que "Modifica la jornada, descanso y composición de la remuneración de los trabajadores de casa particular, y probibe la exigencia de uniforme en lugares públicos". Con esta modificación legal las trabajadoras consiguieron una mejora sustantiva, una "desprecarización", de sus condiciones de trabajo y de empleo. Pese a la necesidad de fiscalizar el trabajo doméstico asalariado que se desarrolla en los hogares del país, para promover el cumplimiento a cabalidad de la nueva normativa, las dirigentas de las organizaciones del gremio concuerdan en que su aprobación fue un éxito y un fruto de su propia movilización.

La presente investigación tiene como objetivo reconstruir el proceso mediante el cual las trabajadoras de casa particular, particularmente las organizadas en SINTRACAP, consiguieron que se aprobara la Ley $\mathrm{N}^{\circ} 20.786$, identificando y analizando las diferentes estrategias sindicales que utilizaron para tal fin. Para el análisis de estas estrategias se utilizará el enfoque de los recursos de poder, en diálogo con las teorías del desarrollo desigual del capital y las teorías de la precariedad del trabajo. Esta síntesis permitirá entender la emergencia y desarrollo de la organización sindical y sus estrategias en base a los roles limitantes o facilitadores que juegan los procesos y regímenes de trabajo en los que laboran los trabajadores y trabajadoras organizados. Así también, la síntesis permitirá entender los efectos estructurantes que las estrategias sindicales pueden jugar sobre las condiciones de trabajo y empleo de los trabajadores y trabajadoras que las protagonizan, "desprecarizando" o no estas condiciones.

Comprender como el SINTRACAP consigue la aprobación de la mencionada legislación se vuelve relevante debido a lo "atípico" del trabajo de casa particular, en tanto se aleja radicalmente del paradigma del trabajo clásico desde el cual se ha construido históricamente el sindicalismo en América Latina $^{1}$. Además, se vuelve relevante debido a que existen una serie de condiciones de trabajo y empleo que dejan a las trabajadoras de casa particular en una posición de "debilidad estructural" a la hora de construir organización y desarrollar sus estrategias: es un trabajo compuesto principalmente por trabajadoras mujeres, que se realiza de manera aislada, con una alta informalidad, bajo relaciones de subordinación emocional, y con escasas posibilidades de negociar colectivamente y generar acciones disruptivas sobre la (re)producción. Así también, el componente migrante y la forma de trabajo puertas adentro son aspectos que dificultan la asociatividad de las trabajadoras y disminuyen su poder ${ }^{2}$.

\footnotetext{
${ }^{1}$ Enrique De la Garza, «Del concepto ampliado de trabajo al sujeto laboral ampliado», en Sindicatos y nuevos movimientos sociales en América Latina, de Enrique De la Garza. Buenos Aires, CLACSO, 2005.

2 . Debido a que solo el 10,4\% de las TCP que trabajan en Chile son extranjeras y solo el 7,7\% de las TCP trabajan bajo la modalidad puertas adentro (CASEN 2017), ambos regímenes del trabajo doméstico no serán considerados en el presente
} 
Pese a la debilidad estructural del gremio de casa particular, desde hace décadas han emergido organizaciones, que si bien nunca han sido masivas -en el sentido de afiliar a porcentajes importantes de las trabajadoras-, si han tratado de representar sus intereses y mejorar sus condiciones de trabajo y empleo. Como se verá a lo largo del artículo, el SINTRACAP, durante los últimos años ha desarrollado sus estrategias sindicales alejándose de la movilización de los recursos de poder asociativos y estructurales, debido a los bajos porcentajes de TCP sindicalizadas en Chile y a la dificultad que tienen de presionar en términos económico a sus empleadores y al Estado. De esta forma, el SINTRACAP se ha alejado de las estrategias sindicales más comunes estudiadas en el país, como las negociaciones colectivas o las huelgas laborales ${ }^{3}$. Por el contrario, el SINTRACAP durante el periodo que va del año 2010 al año 2014 -luego del recambio de los liderazgos sindicales de la organización hasta la aprobación de la Ley $\mathrm{N}^{\circ} 20.786-$, moviliza poderes "externos" a su misma organización, estableciendo alianzas con otras organizaciones y sindicatos del gremio, movilizando la institucionalidad internacional para presionar al Estado chileno y generando alianzas, intercambios y algunas presiones hacia los actores políticos para que aprueben reformas a su favor.

El presente artículo se enmarca en la tradición de la sociología del trabajo y de los estudios del sindicalismo, los cuales, desde mediados de los años dos mil "resurgen", en paralelo a la incipiente revitalización sindical del país 4 . Con este auge, el estudio de los procesos de organización de los trabajadores y las trabajadoras toma un lugar central en la sociología del trabajo, cuestionando las tesis que hablaban del fin del movimiento de trabajadores, de la conflictividad laboral y/o de la imposibilidad de organización ante situaciones laborales precarias ${ }^{5}$. Si bien la bibliografía ha mostrado estas posibilidades de organización en variados sectores, estos análisis suelen centrarse en sectores de trabajadores clásicos y, en general, con un alto o medio poder estructural ${ }^{6}$. Es decir, sectores de trabajadores con altas posibilidades disruptivas sobre la producción, centralizados geográficamente por la naturaleza de sus procesos de trabajo y/o con relaciones de trabajo formales y más o menos estables.

Frente al mencionado estado de los estudios sindicales en el país, la investigación intenta ir más allá de los sectores de trabajadores con alto poder estructural, como ya algunos lo han comenzado a hacer en los últimos años ${ }^{7}$ y, más allá de las clásicas formas de acción sindical basadas en la movilización del poder estructural. Se ha escogido el sector de las trabajadoras de casa particular por su marcada debilidad estructural (incapacidad disruptiva, procesos de trabajo descentrados y desconcentrados, feminización del sector e informalidad) y, porque pese a esta, se han organizado desde hace años colectivamente, movilizando poderes escasamente estudiados por los estudios del trabajo ${ }^{8}$. Si otros autores y autoras han

artículo. Tanto los datos de la encuesta CASEN como los datos de otras encuestas utilizadas a lo largo del artículo se encuentran ponderados con los factores de expansión correspondientes.

3 Dirección del Trabajo, op. cit.; OHL, op. cit..

4 Antonio Aravena, «La recuperación de los estudios laborales en Chile (1990-2014)», en Los estudios laborales en América Latina, de Enrique De la Garza, 2016, 103-126.

5 Aravena, op. cit.; Francisca Gutiérrez, «Oportunidades y peligros del pluralismo sindical en el Chile post-transición», Nuevo Mundo Mundos Nuevos. Nouveaux mondes mondes nouveaux-Novo Mundo Mundos Novos-New world New worlds, 2013.

6 Aravena y Núñez, op. cit.; Carolina Bank, Building Power from Below: Chilean Workers Take On Walmart. Cornell University Press, 2017; Omar Manky, «Resource Mobilisation and Precarious Workers' Organisations: An Analysis of the Chilean Subcontracted Mineworkers' Unions», Work, Employment and Society 32, n.o 3, 2018, 581-98; Camilo Santibáñez y Frank Gaudichaud, «Los obreros portuarios y la idea de "posición estratégica" en la postdictadura chilena (2003-2014)», en Trabajadores y trabajadoras. América en movimiento, 2017.

7 Bank, op. cit.; Rodrigo Henríquez, «Manipuladoras. Conflicto y acción sindical efectiva en trabajadoras del servicio de alimentación escolan». Documentación, Publicaciones y Estadísticas, Dirección del Trabajo. Gobierno de Chile, 2017; Ximena Valdés, Carmen Godoy, y Angie Mendoza, «Acción colectiva y resistencia: asalariadas agrícolas en Chile frente a la precarización laboral.», Revista Irquierdas 35, 2017: 167-98.

8 Las excepciones son Manky, op. cit.. y, parcialmente, Joel Stillerman, «Explaining Strike Outcomes in Chile: Associational Power, Structural Power, and Spatial Strategies», Latin American Politics and Society 59, n. ' 1, 2017, 96-118. 
estudiado la movilización política internacional de las TCP latinoamericanas ${ }^{9}$, las resistencias de las latinas en New York ${ }^{10}$ y las comunidades de empoderamiento y concientización de las migrantes en Londres ${ }^{11}$, era el turno de estudiar las estrategias sindicales de las TCP que trabajan en Chile.

\section{Marco teórico}

\section{Esquema 1}

\section{Procesos de organización sindical: estructura del trabajo, acción sindical y resultados de la acción.}

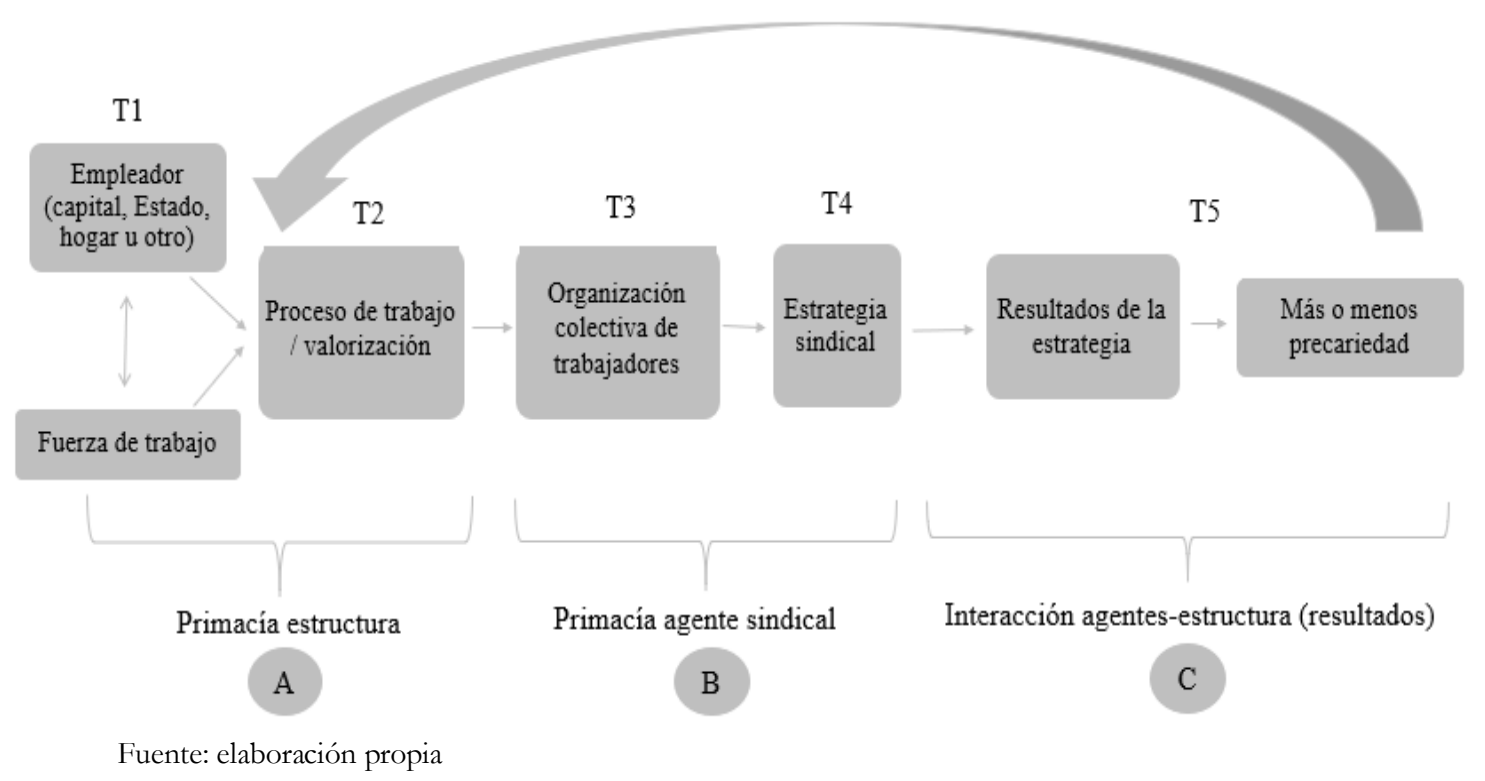

El marco teórico utilizado es síntesis del enfoque de los recursos de poder ${ }^{12}$, las teorías "decoloniales" de la precariedad laboral ${ }^{13}$ y las teorías del desarrollo desigual del capital ${ }^{14}$. La vinculación de las estrategias sindicales con las estructuras que las constriñen y con las estructuras que consiguen

${ }^{9}$ Mary Goldsmith, «Los espacios internacionales de la participación política de las trabajadoras remuneradas del hogar», Revista de Estudios Sociales, n.o 45 (2013): 233-46.

${ }_{10}$ Carlos Piñeyro, «Organización, emociones y resistencia de las trabajadoras del hogar latinas y caribeñas en la Ciudad de Nueva York, Estados Unidos», Revista Latinoamericana de Antropología del Trabajo 3 (2018).

11 Joyce Jiang, «Organizing Immigrant Workers Through 'Communities of Coping': An Analysis of Migrant Domestic Workers' Journey from an Individual Labour of Love to a Collective Labour with Rights», en Global Perspectives on Workers' and Labour Organizations (Springer, 2018), 23-42.

12 Erik Olin Wright, «Working-class power, capitalist-class interests, and class compromise», American Journal of Sociology 105, n. ${ }^{\circ}$ 4 (2000): 957-1002; Beverly J. Silver, Fuerzas de trabajo: los movimintos obreros y la globalización desde 1870 (Madrid: Ediciones AKAL, 2005); Stefan Schmalz, «Los recursos de poder para la transformación sindical», Nueva sociedad, n.o 272 (2017): 19-41; Carmen Ludwig, Edward Webster, y Stefan Schmalz, «The Power Resources Approach: Developments and Challenges», 2018.

13 Dasten Julián Vejar, «Precariedad laboral y repertorios sindicales en el neoliberalismo: Cambios en la politización del trabajo en Chile», Psicoperspectivas. Individuo y Sociedad 17, n. 1 (2018); Brett Neilson y Ned Rossiter, «Precarity as a Political Concept, or, Fordism as Exception», Theory, Culture \& Society 25, n.o 7-8 (2008): 51-72; Maurizio Atzeni y Immanuel Ness, eds., Global Perspectives on Workers' and Labour Organizations, Work, Organization, and Employment (Springer Singapore, 2018).

14 Silvia Federici, El patriarcado del salario. Críticas feministas al marxismo (Traficante de Sueños, 2018); David Harvey, Diecisiete contradicciones y el fin del capitalismo (IAEN-Instituto de Altos Estudios Nacionales del Ecuador, 2014); Wright, «Working-class power, capitalist-class interests, and class compromise»; Silver, Fuerzas de trabajo: los movimientos obreros y la globalización desde 1870. 
modificar es el centro del marco propuesto. En específico, la propuesta teórica tiene tres componentes o momentos de análisis elementales, que pueden observarse en el Esquema 1: (A) Momento de primacía estructural, que refiere a las características estructurales del trabajo realizado por los socios y socias del sindicato que se analizará, (B) Momento de primacía del agente, que refiere a las características de la organización sindical emergente en el mencionado contexto estructural y al desarrollo de sus estrategias sindicales, y (C) Momento de interacción acción-estructura, que refiere a los resultados de la estrategia sindical en relación con la precariedad laboral.

Según Erik Olin Wright ${ }^{15}$, el poder de los trabajadores (y las trabajadoras) emerge tanto por la voluntad y autoorganización de los trabajadores, como también, por las posiciones "estructurales" que ocupan los trabajadores (y las trabajadoras) en el mercado de trabajo y en el lugar de producción. Si bien el autor marxista dejó hasta este punto el análisis del poder estructural (para dedicarse a estudiar la relación entre poder asociativo, interés de clase y compromiso de clase al nivel del Estado-Nación), autores como Silver ${ }^{16}$, Dörre ${ }^{17}$ o Schmalz ${ }^{18}$, dentro del mismo enfoque de los recursos de poder, o Womack ${ }^{19}$, Federici ${ }^{20}$, Atzeni y Ness ${ }^{21}$ y Harvey ${ }^{22}$, desde tradiciones paralelas y dispersas que se podrían agrupar como del "desarrollo desigual del capital", han desarrollado esta dimensión del poder. El argumento general consiste en argumentar que, debido a los desplazamientos y desarrollos desiguales del capital, los trabajadores y las trabajadoras ocupan posiciones diversas en los procesos y regímenes de trabajo, y en los distintos ciclos del capital. Esta diversidad "estructural” hará más fácil o difícil la organización antagonista de los trabajadores, como también, les dará más o menos poderes posibles de movilizar en sus estrategias. Así, es factible hablar de trabajadores "estructuralmente fuertes" y trabajadores "estructuralmente débiles". Los trabajadores estructuralmente fuertes son los obreros que por las características de los regímenes y procesos de trabajo en los que laboran tienen facilidades para organizarse en comparación con otros obreros (tienen contratos de trabajo estables y se encuentran concentrados en un mismo lugar de trabajo), como también, tienen posibilidades de presionar a sus empleadores y a otros actores por su importancia en una cadena de reproducción - producción distribución.

Pese a las mencionadas determinaciones del "momento de primacía estructural" del esquema teórico propuesto, las organizaciones de trabajadores y trabajadoras pueden emerger en cualquier contexto laboral y a distintos niveles ("momento de primacía del agente"). Las organizaciones de trabajadores y trabajadoras pueden desarrollarse al nivel del lugar de trabajo (consejo de fábrica), al nivel de empresa o rama económica (sindicato) y/o al nivel nacional (partido) ${ }^{23}$. Pero esto no es todo, a partir de la obra fundante de Wright, que distinguía solamente el poder estructural del poder asociativo, se ha desarrollado un complejo enfoque para el análisis de los recursos de poder movilizados por los sindicatos en sus estrategias, cuyos últimos desarrollos, en base a una serie de investigaciones en diferentes contextos tanto del Norte como el Sur Global, han señalado la existencia de cuatro grandes "recursos de poder". Estos recursos son los "asociativos", los "sociales", los "estructurales" y los "institucionales"24.

El poder asociativo es el más simple que los trabajadores pueden movilizar a nivel sindical. Este poder es el que comienza a emerger cuando los obreros se asocian para solucionar sus problemas de

\footnotetext{
15 Wright, op. cit.

16 Silver, op. cit.

${ }^{17}$ Klaus Dörre, Hajo Holst, y Oliver Nachtwey, «Organising-A strategic option for trade union renewal? », International Journal of Action Research 5, n.o 1 (2009): 33-67.

18 Schmalz, op. cit.

${ }^{19}$ John Womack, «Posición estratégica y fuerza obrera», Hacia una nueva historia de los movimientos obreros. FCE, México, 2007.

${ }^{20}$ Federici, op. cit.

21 Atzeni y Ness, op. cit.

22 Harvey, op. cit.

23 Wright, op. cit.

${ }^{24}$ Ludwig, Webster, y Schmalz, op. cit.; Schmalz, op. cit.
} 
manera colectiva. Este recurso le puede otorgar a los trabajadores organizados diferentes grados de poder según el número de trabajadores organizados, su representatividad, la estabilidad y fortaleza orgánica de su asociación, la disposición de los trabajadores para movilizarse colectivamente y para demostrar en los hechos este poder (mediante marchas o concentraciones, por ejemplo), la eficacia de la organización, sus recursos infraestructurales, su cohesión interna, entre otras cuestiones ${ }^{25}$.

El poder social de los trabajadores emerge de la interacción y cooperación de los sindicatos con otros actores sociales, como también del apoyo de sus exigencias por parte de la sociedad en general. Schmalz le llamará "poder de cooperación" a la primera dimensión y "poder de discurso" a la segunda ${ }^{26}$. El poder de cooperación se puede entender de forma más amplia a como lo entienden los teóricos de los recursos de poder, en el sentido que los sindicatos pueden aumentar su poder no solo relacionándose y siendo apoyados por movimientos sociales, sino que también pueden fortalecerse por el apoyo que reciben de partidos y líderes políticos que, a cambio de la movilización de votos, u otras cuestiones, pueden legislar para sus intereses ${ }^{27}$, como también pueden beneficiarse de la cooperación que puedan establecer con sus empleadores. Del tipo de redes o cooperaciones que los sindicatos movilicen se desprende el tipo de estrategia que los sindicatos adoptarán. De esta forma, si el sindicato basa su acción en la cooperación con otros sindicatos y movimientos sociales, ocupará una estrategia movimientista o de movimiento social. Si el sindicato basa su acción en la cooperación, alianza o intercambio con actores políticos ocupará la estrategia de acción sindical política ${ }^{28}$. Y, por último, si el sindicato basa su acción en la cooperación con sindicatos, federaciones u otras organizaciones internacionales, ocupará la estrategia de solidaridad internacional.

El poder estructural, en tanto posición, como ya se ha mencionado, refiere a la facilidad que los trabajadores tienen para organizarse y a la potencialidad que los mismos tienen por su situación o lugar en el sistema económico. El poder estructural como "recurso" de poder movilizable se basa en el poder disruptivo ${ }^{29}$, y con ello, en el poder de los trabajadores de interrumpir o limitar el beneficio del capital, siendo la huelga laboral la clásica forma de expresión. Gracias a los aportes de las teorías feministas marxistas ${ }^{30}$ y de las teorías de las cadenas globales de valor ${ }^{31}$, el poder estructural o de "producción" se puede pensar en sentido amplio, tanto en el proceso productivo como en otros puntos del ciclo del capital, como la reproducción y distribución. Es decir, los trabajadores además del poder estructural en el lugar de producción pueden tener y ejercer el poder de distribución y de reproducción ${ }^{32}$.

Por último, el poder institucional es el resultado de las diferentes luchas de los trabajadores y trabajadoras que, a su vez, se basan en el poder estructural, social y asociativo ${ }^{33}$. Este poder les concede derechos a los sindicatos, pero al mismo tiempo les pone límites a sus capacidades de actuar ${ }^{34}$. A nivel nacional el poder institucional se expresa típicamente en la Constitución y la legislación laboral, a nivel internacional en Convenios o Tratados, a nivel interempresa en los convenios colectivos interempresa o por rama económica, y a nivel de empresa en contratos individuales y colectivos. Cuando los trabajadores

\footnotetext{
${ }^{25}$ Ludwig, Webster, y Schmalz, op. cit.

${ }^{26}$ Schmalz, op. cit.

${ }^{27}$ Kerstin Hamann y John Kelly, «Union Revitalization through Political Action? Evidence from Five Countries», en IRRA 55TH ANNUAL PROCEEDINGS, 2003; Richard Hyman y Rebecca Gumbrell-McCormick, «Trade unions, politics and parties: is a new configuration possible?», Transfer: European Review of Labour and Research 16, n. 3 (2010).

${ }_{28}^{2}$ No confundir la "acción sindical política" con la "acción política de la clase trabajadora", esto es, cuando los trabajadores y las trabajadoras se dotan "autónomamente" de sus propias herramientas políticas para entrar en la arena política y eventualmente establecer compromisos de clase.

${ }^{29}$ Schmalz, op. cit.

${ }^{30}$ Federici, El patriarcado del salario.

31 Bank, op. cit.

32 Schmalz, op. cit.

33 Schmalz, op. cit.

${ }^{34}$ Ludwig, Webster, y Schmalz, «The Power Resources Approach».
} 
movilizan el poder institucional hacen referencia y/o realizan acciones basadas en estos derechos codificados, tanto en instancias locales, empresariales, nacionales e internacionales.

El marco teórico utilizado sostiene que recursos de poder de los trabajadores y trabajadoras se encuentran desigualmente distribuidos entre estos, debido al desarrollo desigual del capitalismo entre y dentro de las naciones ${ }^{35}$, como también por el diverso grado de poder auto generado por los trabajadores en base a su organización histórica (poder institucional) y actual (poder asociativo y social). Es decir, no todos los trabajadores tendrán los mismos poderes a la hora de actuar. Pero también, pese a tener determinados poderes, o eventualmente poderlos generar, los trabajadores no necesariamente ocuparán todos sus poderes, pues hay diversas consideraciones y capacidades estratégicas a la hora de movilizarlos ${ }^{36}$ y, también, determinadas orientaciones ideológicas que los pueden hacer vetar o seleccionar a priori ciertos poderes $^{37}$.

El tercer y último elemento del marco teórico (Esquema 1), "los resultados", intenta mostrar que los sindicatos no se organizan porque si, sino porque perciben injusticias, identifican a los "culpables" de las mismas y piensan que sus condiciones de vida pueden mejorar ${ }^{38}$. Esto implica que las estrategias sindicales pueden evaluarse en relación con su eficacia ${ }^{39}$, es decir, se pueden evaluar con relación a que tanto mejoran o "desprecarizan" las condiciones de empleo y trabajo de los obreros y obreras. Siguiendo las dimensiones de la precariedad de Julián ${ }^{40}$, la desprecarización puede ir en a lo menos cinco sentidos: desprecarización contractual, desprecarización de la seguridad social, desprecarización salarial, desprecarización de las condiciones de trabajo y desprecarización de la carga e intensidad de trabajo ${ }^{41}$.

\section{Marco metodológico}

La presente investigación es un estudio caso $^{42}$, específicamente un estudio de un proceso de organización sindical. Los "procesos de organización sindical" serán entendidos como un conjunto de estrategias llevadas a cabo por organizaciones de trabajadores (sindicatos) con el objetivo, y eventual efecto, de mejorar sus condiciones de trabajo (desprecarizarlas). Esto, en el marco de relaciones de empleo y de trabajo estructuradas por las dinámicas del capital y por las resistencias sindicales y no sindicales anteriores de los trabajadores y trabajadoras que participan de las mismas relaciones.

La investigación es analítica y de "proceso" 43 pues solo se ocupa selectivamente de ciertos aspectos del caso estudiado (las debilidades estructurales, las estrategias y los resultados de estas), se estructura en el sentido de que el investigador está desarrollando una explicación analítica basada en un marco teórico específico, y el objetivo de la investigación consiste en ofrecer una explicación narrativa de

\footnotetext{
35 Silver, op. cit.

36 Christian Lévesque y Gregor Murray, «Understanding union power: resources and capabilities for renewing union capacity», Transfer: European Review of Labour and Research 16, n.' 3, 2010, 333-350.

${ }^{37}$ Ralph Darlington, «Leadership and Union Militancy: The Case of the RMT», Capital \& Class 33, n..$^{3}$, 2009, 3-32

38 John Kelly, Retbinking industrial relations: Mobilisation, collectivism and long waves (Routledge, 2012).

39 Paul F. Clark, Building more effective unions (Cornell University Press, 2013).

40 Dasten Julián Vejar, «Precariedad laboral y repertorios sindicales en el neoliberalismo: Cambios en la politización del trabajo en Chile», Psicoperspectivas. Individuo y Sociedad 17, n. 1 (2018).

41 Tanto Julián como el autor del presente texto, para definir y entender el concepto de precariedad se basan en las teorías "decoloniales" del fenómeno. Es decir, teorías que entienden a la precariedad como una condición estructural y constante de las sociedades periféricas como la chilena; que entienden a la precariedad como una forma de gobierno y división de la clase trabajadora, aunque solo afecte a una parte de esta, pues toda la clase tiene "miedo" de que sus condiciones de empleo y trabajo se precaricen; y que entienden a los estados de bienestar y a los regímenes de trabajo fordistas como excepciones más que normas en las sociedades tanto del Norte como del Sur Global. Neilson y Rossiter, op. cit.; Atzeni y Ness, op. cit.

42 Xavier Coller, Estudios de caso, Cuadernos metodológicos 30 (Madrid, España. Centro de Investigaciones Sociológicas, 2000); Robert E. Stake, Investigación con estudio de casos (Ediciones Morata, 1998); Pascal Vennesson, «Estudios de caso y seguimiento de procesos: teorías y prácticas», en Enfoques y metodologías de las ciencias sociales: una perspectiva pluralista (Akal, 2013), $237-254$.

43 Vennesson, op. cit.
} 
un itinerario causal que conduce a un resultado determinado. Esto es, explicar según los recursos de poder de SINTRACAP la aprobación de la Ley N²0.786.

Tanto para lograr un conocimiento en profundidad del estudiado, como para evitar la intromisión de "sesgos personales del investigador y de los informantes" 44 , se recurrió a la técnica de triangulación de la información, la cual consiste en comprobar las informaciones recibidas y producidas, tanto de los informantes como de los documentos, con varias fuentes. Esta triangulación llevó al investigador a usar una gran cantidad y variedad de fuentes de información, las cuales son tanto de carácter "cuantitativas" como "cualitativas". Estas fuentes fueron:

(1) Documentos: contratos de trabajo individuales, la historia de la Ley $\mathrm{N}^{\circ} 20.786$ de la Biblioteca del Congreso Nacional, la Ley N²0.706, el Convenio 189 de la Organización Internacional del Trabajo (OIT), notas de prensa del periodo 2008-2014 $\left(\mathrm{N}^{\circ} 12\right)^{45}$, cuadernillo de antecedentes históricos (1989) y estatutos sindicales de SINTRACAP (2003), información de la página web de SINTRACAP46 y del Facebook de la presidenta de la organización.

(2) Bases de datos: datos administrativos de la Dirección del Trabajo sobre contratos de trabajo registrados (2015-2018), datos de la Encuesta Nacional de Empleo (2010-2019) del Instituto Nacional de Estadísticas (INE) y datos de la Encuesta CASEN 1990-201747.

(3) Entrevistas y grupos focales: dos entrevistas semi estructuradas a las principales dirigentas de SINTRACAP, un grupo focal con dirigentas y socias de la misma organización y once entrevistas semi estructuradas con trabajadoras de base sindicalizadas y no sindicalizadas, de la Región Metropolitana y de Los Lagos ${ }^{48}$.

(4) Observación participante y no participante, primero como investigador y luego como asesor, del SINTRACAP durante los años 2017-2019.

\section{Resultados}

\subsection{La Ley $\mathrm{N}^{\circ} 20.786$ como reforma desprecarizante}

La historia del Sindicato Interempresa de Trabajadoras de casa particular (SINTRACAP) es larguísima, en tanto la organización tiene sus orígenes en 1947. Desde esa fecha hasta ahora el sindicato se ha mantenido activo, atravesando y sobreviviendo múltiples coyunturas políticas y económicas que, si bien a veces han potenciado su desarrollo, otras tantas lo han limitado ${ }^{49}$. La última coyuntura desfavorable que vivió el sindicato fue la dictadura militar chilena (1973-1989), la cual restringió la movilización opositora de los trabajadores y bloqueó el acceso de los sectores populares al Estado ${ }^{50}$.

\footnotetext{
${ }^{44}$ Coller, op. cit., 56

45 Se analizaron todas las notas encontradas a partir de los conceptos "Sintracap", "trabajadoras de casa particular" o "Ley N²0.786", y que hicieran referencia en su contenido al proceso de organización sindical.

46 http://sintracapchile.cl/

47 Todos los datos mencionados, menos los administrativos, fueron ponderados por los factores de expansión correspondientes. 48 Estas entrevistas fueron realizadas en el marco de otro proyecto de investigación sobre condiciones de trabajo, mecanismos de control y formas de resistencia de las trabajadoras de casa particular en Chile (financiado por el Fondo de Iniciación a la Investigación de la DAE FACSO Universidad de Chile).

${ }^{49}$ Elizabeth Quay Hutchison, «Identidades y Alianzas: El movimiento chileno de las Trabajadoras de Casa Particular durante la Guerra Fria), Nuevo Mundo Mundos Nuevos. Nouveaux mondes mondes nouveaux - Novo Mundo Mundos Novos - New world New worlds; SINTRACAP, Cuadernillo de antecedentes históricos de SINTR ACAP. Área metropolitana. 22-8-89, 1989.

${ }^{50}$ Manuel Antonio Garretón, Hacia una nueva era política: estudio sobre las democratizaciones (Fondo de Cultura Económica, 1995).
} 
Recién a inicios de los noventa, cuando el sistema político vuelve a abrirse a las demandas de los sectores populares -al menos parcialmente-51, las trabajadoras de casa particular (TCP) comienzan a lograr modificaciones legales a su favor, que poco a poco irán mejorando sus condiciones de trabajo e igualando sus regímenes de trabajo a los de los otros trabajadores del país. Estas modificación son: la Ley N¹9.010 que crea el Sistema de indemnización a todo evento para las TCP (1991), la Ley N¹9.591 que les extiende derechos de maternidad (1998), la Ley $\mathrm{N}^{\circ} 20.279$ que las reconoce como trabajadoras con derecho a recibir a lo menos el 100\% del Ingreso Mínimo Mensual (IMM) (2008) ${ }^{52}$, la Ley No20.336 que les extiende el derecho a feriados (2009), y la Ley N²0.786 que modifica la jornada, descansos y composición de la remuneración de las TCP (2014).

La última modificación legal mencionada ha sido una de las más importantes reformas para el gremio, en tanto desprecariza la labor de las TCP en términos salariales, de carga de trabajo y de seguridad social ${ }^{53}$. Esto, debido a que la legislación obliga a la formalización contractual de la relación laboral entre las TCP y sus empleadores, lo que les permite a las primeras gozar de indemnización a todo evento en caso de que la relación laboral termine y de gozar de seguridad social54; obliga a las partes a negociar y especificar en el contrato de trabajo individual las labores específicas por las que se contrata a la TCP; garantiza la no obligación para la trabajadora de usar delantal afuera del hogar; obliga al empleador a realizar el pago de salario en moneda de curso legal, sin descontar alojamiento y comidas al sueldo de la trabajadora; disminuye la jornada laboral de las TCP puertas afuera de 72 a 45 horas semanales, limita las horas extra que pueden realizar a 15 a la semana (voluntarias y con un recargo de un $50 \%$ de su valor) y tienen los domingos como días libres; y les asegura a las TCP puertas adentro un descanso mínimo diario de 12 horas (8 horas ininterrumpidas) y les asegura los días sábados y domingos libres (el sábado puede ser fraccionado o cambiado por mutuo acuerdo de las partes).

\subsection{Las debilidades estructurales del trabajo de casa particular en Chile}

Aunque la Ley N²0.786 y sus antecesoras modificaciones legales hayan "desprecarizado" una serie de aspectos de las condiciones de trabajo y empleo de las trabajadoras de casa particular, existen varias características estructurales de esta labor que se mantienen y que dificultan la asociatividad sindical de las trabajadoras del gremio. Para organizarse sindicalmente el SINTRACAP les debe hacer frente a estas condiciones y desarrollar estrategias sindicales que no contemplan la movilización de recursos de poder estructurales, pues carecen de ellos.

La primera "debilidad estructural” tiene que ver con la descentralización y desconcentración del proceso de trabajo de casa particular. Estas trabajadoras suelen labrar de forma aislada, e invisibilizada espacialmente ${ }^{55}$, en alguno de los más de 250.000 hogares que recurren al trabajo doméstico asalariado. En específico, la descentralización se da debido a que más del 86\% de las TCP trabajan solas en el hogar que las contrata, sin compañeras de trabajo, según datos de la CASEN 2017. La desconcentración de este trabajo se da debido a que no hay una unidad empleadora que contrate y reúna a las trabajadoras en un mismo lugar, de ahí que frente a cualquier problema o intento de resistencia en el lugar de trabajo, la trabajadora se encuentra sola frente a un empleador(a) y su eventual familia. El proceso de trabajo de casa particular no les permite a las trabajadoras crear lazos de cooperación y solidaridad en el mismo

\footnotetext{
51 Manuel Antonio Garretón, Neoliberalismo corregido y progresismo limitado. Los gobiernos de la Concertación en Chile, 1990-2010, 2013.

52 Hasta el 2008 a las trabajadoras se les podía pagar el 75\% del salario mínimo nacional.

53 Dimensiones de la precariedad de Julián, op. cit.

${ }^{54}$ La privatización y administración de los fondos de pensiones por las AFP relativiza el carácter "asegurador" y, por ende, "desprecarizante", de la seguridad social en Chile.

55 Galvez y Todaro, op. cit.; Erin Hatton, «Mechanisms of Invisibility: Rethinking the Concept of Invisible Work», Work, Employment and Society 31, no 2 (2017): 336-51; Valenzuela y Sánchez, op. cit.»; Jiang, op. cit.».
} 
trabajo, estos deben construirlos hacia afuera de este proceso, con una serie de esfuerzos y tiempos extras $^{56}$.

Pese a que Chile, dentro de América Latina, presenta una de las más altas tasas de formalización contractual del trabajo de casa particular ${ }^{57}$, esta se encuentra en torno al $50 \%$ de las trabajadoras ${ }^{58}$. Esta cifra indica que solo la mitad de las trabajadoras de casa particular tiene contrato de trabajo formal y acceso a la seguridad social, lo que las deja en una posición de fragilidad frente a enfermedades, despidos, jubilación o requerimientos de sobre trabajos por parte de los empleadores o empleadoras. Pero también, las deja en una posición de debilidad que dificulta la asociatividad de las trabajadoras. El no tener contrato formal funciona como mecanismo legal de invisibilización del trabajo ${ }^{59}$, en tanto a la trabajadora se le niega desde el Estado la condición de trabajadora y, por ende, de organización. Además, le permite al empleador despedirla sin mayores problemas si le molesta que la trabajadora intente organizarse sindicalmente.

Desde una perspectiva teórica que ve al trabajo doméstico como un trabajo de reproducción, que es condición del trabajo asalariado por el capital ${ }^{60}$, las trabajadoras de casa particular tendrían una importante potencia disruptiva o "poder de reproducción" ${ }^{1}$, pero desde la experiencia histórica de los sindicatos de trabajadoras de casa particular de Chile esta posibilidad es relativizada. En el país las TCP sindicalizadas son poquísimas ${ }^{62}$ y solo se han movilizado los domingos, días generalmente libres para las trabajadoras de casa particular ${ }^{63}$. Las movilizaciones desarrolladas por las TCP no han afectado a los hogares de sus empleadores, tanto en el pasado lejano ${ }^{64}$ como en el periodo actual: "no nos concentramos en eso. La razón es porque no sería efectiva po. Las chiquillas tienen mucho miedo de quedarse sin trabajo. No es muy masiva. Lo máximo que sacamos una vez fue como 500 trabajadoras" 65.

Por último, el componente altamente personalizado de la relación laboral de casa particular conlleva dimensiones afectivas y emocionales ${ }^{66}$, que fomentan y permiten el intercambio de favores entre las trabajadoras casa particular y sus empleadores, y el chantaje emocional de estos últimos sobre las primeras. Esta relación afectiva entre las partes de la relación laboral puede percibirse como pasada a llevar, por parte del empleador, si la trabajadora participa de acciones sindicales.

Todas las debilidades estructurales mencionadas dificultan de cierta forma la asociatividad de las trabajadoras de casa particular. La mayor expresión de esta baja asociatividad se encuentra en el dato de que menos de un $1 \%$ de las TCP en Chile se encuentran sindicalizadas ${ }^{67}$, y que organizaciones como SINTRACAP, pese a su larga historia, cuenta con solamente 500 socias, de las cuales una cifra considerablemente menor participa activamente de la organización.

\subsection{Las estrategias sindicales del SINTRACAP (2010-2014)}

La importante desprecarización que lograron las trabajadoras de casa particular el 2014 con la aprobación de la Ley $\mathrm{N}^{\circ} 20.786$ no se entiende sin la acción sindical concertada de las trabajadoras del

56 Andrea Del Campo y Soledad Ruiz, «Empoderamiento de Trabajadoras de Casa Particular Sindicalizadas», Psykhe (Santiago) 22, n. ${ }^{\circ} 1,2013,15-28$.

${ }^{57}$ Mary Goldsmith, «Los espacios internacionales de la participación política de las trabajadoras remuneradas del hogar», Revista de Estudios Sociales, n. ${ }^{\circ}$ 45, 2013: 233-46; Valenzuela y Sanches, op. cit.

58 Boccardo et al., op. cit,; CASEN 2017; Encuesta Nacional de Empleo (2010-2019).

${ }^{59}$ Hatton, op. cit.; Valenzuela y Sánchez, op. cit..

${ }^{60}$ Federici, op. cit.

${ }^{61}$ Schmalz, op. cit.

62 Menos del 1\% según los datos de la CASEN 2017.

63 Biobío Chile, 2011; El Ciudadano, 2011; OIT, 2014.

${ }^{64}$ SINTRACAP, 1989.

${ }^{65}$ Entrevista Dirigenta SINTRACAP, 2017.

${ }^{66}$ Gálvez y Todaro, op. cit.; Valenzuela y Sanches, op. cit.

${ }^{67}$ Según la CASEN 2017. 
gremio. El proceso de organización sindical que dio como resultado la mencionada modificación legal tiene sus orígenes el año 2010, tras unos años de haberse renovado la directiva sindical. En este periodo las trabajadoras desarrollaron tres estrategias sindicales, en las destaca la movilización de los siguientes poderes: (1) el poder internacional-institucional, mediante la participación con la CONLACTRAHO 68 en la OIT, lo que les permitió conseguir la aprobación del Convenio 189, con el cual posteriormente presionaron al Estado de Chile. (2) El poder social-sindical y social-discurso, pues todo el proceso de organización sindical no lo llevó a cabo de forma aislada el SINTRACAP, sino que en alianza con los SINTRACAP de regiones y con otras dos organizaciones del gremio (ANECAP y SINDUCAP). Además, debido a una serie de abusos hacia las TCP que estallaron a fines del año 2011, las problemáticas de estas trabajadoras se encontraban en la opinión pública y fueron eficazmente movilizadas por el sindicato. (3) El poder político y medianamente el asociativo, mediante la participación en instancias de discusión parlamentarias, en mesas de trabajo con el ejecutivo, lobby con parlamentarios, apoyo a la candidata presidencial que apoyaba sus demandas y también con movilizaciones sociales de baja intensidad para presionar a los mismos actores políticos.

\subsection{La movilización del poder institucional-internacional}

En el año 1987, distintas organizaciones de trabajadoras de casa particular de América Latina crean la CONLACTRAHO, la Confederación Latinoamericana y del Caribe de Trabajadoras del Hogar, siendo la primera organización regional de trabajadores del hogar en el mundo ${ }^{69}$. La participación de las TCP en la CONLACTRAHO les ha permitido modificar la institucionalidad laboral internacional, para así presionar posteriormente la modificación de las institucionalidades nacionales particulares de cada país, y también, el generar lazos asociativos entre las distintas organizaciones de TCP de Latinoamérica, compartiendo experiencias y saberes ${ }^{70}$. La organización ha sido muy útil para los sindicatos de los diversos países de América Latina y El Caribe, pues les ha permitido sobrellevar la fragilidad de sus organizaciones -en general pequeñas y poco burocráticas-, fortaleciéndose por medio de una organización a escala regional. Al menos hasta 2013, participaban de la organización regional organizaciones de Argentina, Bolivia, Brasil, Canadá, Chile, Colombia, Costa Rica, Ecuador, Guatemala, México, Paraguay, Perú, República Dominicana y Uruguay ${ }^{71}$.

Además, mediante la participación en esta organización, después de un fuerte Lobby político internacional, muy bien descrito por Goldsmith (2013), las TCP consiguieron la aprobación del Convenio 189 por parte de la OIT (2011), el que les garantiza descansos, salario mínimo, formalidad contractual, entre otras cuestiones, a las TCP de los países que ratifican el convenio. Las trabajadoras de Chile movilizaron este convenio internacional a su favor para concretar sus demandas frente al Estado, en tanto el gobierno de Chile votó a favor del Convenio en la OIT el 201172. El Convenio les permitió a las TCP tener un respaldo en la normativa internacional, un referente de lo que debiese ser "justo" o "decente", para embarcarse en la lucha por la obtención de la Ley 20.786 en 2014. Las mismas dirigentas de las TCP afirman que la Ley 20.786 hace carne este Convenio Internacional. En general, sus disposiciones son representadas por la Ley $20.786^{73}$.

Las Conferencias Internacionales anuales de la OIT se realizan en Ginebra, y en ellas, se analizan los cumplimientos y la violación de las normas internacionales en cada país, como también, se elaboran y adoptan instrumentos internacionales como convenios y recomendaciones. En la discusión del

\footnotetext{
${ }_{68}$ Confederación Latinoamericana y del Caribe de Trabajadoras del Hogar.

${ }^{69}$ Goldsmith, op. cit.

70 Cuaderno de Campo, 2018.

71 Goldsmith, op. cit.

72 Goldsmith, op. cit.

73 Cuaderno de Campo, 2018.
} 
Convenio 189, las trabajadoras asociadas a la CONLACTRAHO no solo estuvieron atentas a las resoluciones de las Conferencias, sino que también participaron activamente de las mesas de trabajo que prepararon la propuesta para la conferencia, presionaron desde las tribunas y, sobre todo, hicieron lobby hacia los delegados sindicales, empleadores y de gobierno de cada país ${ }^{74}$.

Probablemente gracias a esta participación de las TCP en las Conferencias de la OIT es que en la Conferencia $100^{\mathrm{a}}$, de junio de 2011, hubo un consenso a favor del convenio y de la recomendación por parte de los distintos grupos regionales de los gobiernos. La aprobación del Convenio fue una victoria mayoritaria para la CONLACTRAHO: "396 a favor, 16 en contra, 63 abstenciones" 75 . Otro dato interesante de la votación es que "a excepción de los delegados de los gobiernos de El Salvador y Panamá, que se abstuvieron, los demás delegados gubernamentales latinoamericanos votaron a favor de la adopción del convenio"76. Así también, de los 25 países que hasta el año 2018 han ratificado el Convenio 189, 13 corresponden a países latinoamericanos. Y de esos 13 países, en 12 hay sindicatos afiliados a la CONLACTRAHO, ¿`será que para que se ratifiquen los Convenios en cada país es necesaria la organización colectiva de las trabajadoras de casa particular? Teniendo en cuenta este panorama latinoamericano no es para nada anormal, entonces, la actitud favorable de los políticos chilenos de todo el espectro político hacia la Ley 20.786 entre los años 2011 y 201477.

\subsection{La movilización del poder social-sindical y social-discurso}

Las alianzas que estableció el SINTRACAP en su proceso de organización sindical para conseguir la aprobación de la Ley no solo fueron de carácter internacional con la CONLACTRAHO, también implicó una alianza constante y la definición de un petitorio único con otras dos organizaciones de trabajadoras asalariadas domésticas del país: la Asociación Nacional de Empleadas de Casa Particular (ANECAP) y el Sindicato Único de Trabajadoras de casa particular (SINDUCAP), con las cuales crearon la entonces llamada "Coordinadora de Trabajadoras de casa particular". Además, el SINTRACAP solidificó sus vínculos con sus "organizaciones hermanas" o "filiales" de cerca de diez diferentes regiones del país, creando el año 2013 la Federación de Trabajadoras de casa particular (FESINTRACAP).

Además, desde el año 2011 el SINTRACAP intento movilizar a su favor la opinión pública gracias a una coyuntura mediática que tiene como epicentro un condominio en un sector acomodado de Chicureo, que discriminaba a las trabajadoras de casa particular obligándolas a ocupar delantales cuando caminaban por los espacios públicos ${ }^{78}$ :

\footnotetext{
Vino a ser hace cuatro años que un acto tan fuera del imaginario que suele tener nuestro país, que se consideraba inclusivo y democrático, puso en la palestra pública el trato indigno a nuestro sector: en las piscinas de los lindos condominios de Chicureo no se permitía que las trabajadoras de casa particular se bañaran, tampoco se permitía el libre deambular por sus territorios sino que debíamos trasladarnos, desde la puerta de entrada a éstos hasta las casas donde desarrollaríamos las labores, en furgones especialmente habilitados para nosotras. Se adujo, ante la denuncia, que los condominios eran demasiado grandes y estaban para la comodidad de las trabajadoras, todos/as sabíamos que detrás de esa normativa lo que subyacía era la sospecha histórica contra nosotras: 'El dateo para los robos'. A este caso siguieron varios en otros lugares del país ${ }^{79}$.
}

\footnotetext{
74 Goldsmith, op. cit.

75 Goldsmith, op. cit.

76 Goldsmith, op. cit.

77 Historia de la Ley N²0.786.

78 Radio Universidad de Chile, 2011.

${ }^{79}$ Ruth Olate, 2014.
} 
Este evento, sucedido a finales del año 2011, como bien señala la misma dirigenta del SINTRACAP RM en su columna de opinión, sorprende a los sindicatos de trabajadoras casa particular revitalizados, con un petitorio claro que expresaba la unidad de la Coordinadora de Trabajadoras de casa particular, y con un instrumento internacional recientemente aprobado por la Organización Internacional del Trabajo (OIT) que legitimaba sus acciones ${ }^{80}$. Gracias a esa coyuntura, y la rápida reacción sindical, las organizaciones tenían para el día 26 de diciembre del 2011 una conferencia de prensa en las afueras del congreso. Desde ahí, las trabajadoras "no pararon” hasta conseguir la Ley N²0.786:

Y partí, al frente del congreso. Había unas cámaras, yo no sé cómo se dio eso. Estaban todos los medios de comunicación escritos, radio y televisión. Nos siguieron todo. Nunca había visto tantas cámaras. Estaba con el papel de medida de protección de las TCP. Desde ahí no paramos. Todos los medios nos tomaron ${ }^{81}$.

\subsection{La movilización del poder político}

\section{Esquema 2}

Historia social de la Ley 20.786. Interacciones entre momentos políticos y organizaciones de trabajadoras de casa particular.
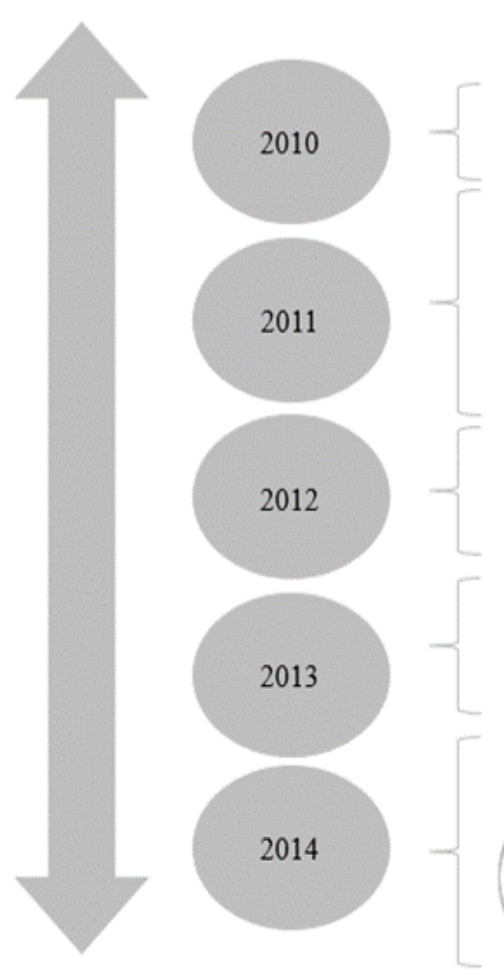

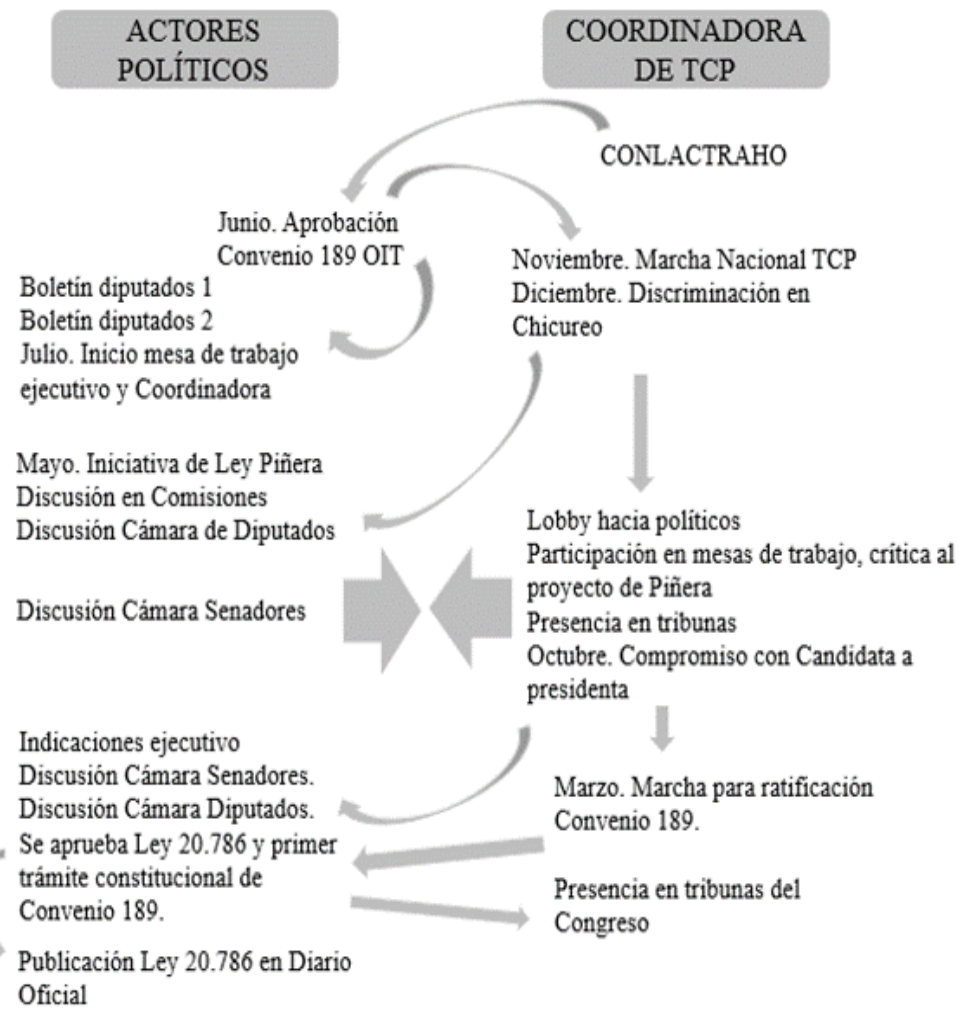

Fuente: elaboración propia

${ }^{80}$ Ruth Olate, 2014.

${ }^{81}$ Entrevista Dirigenta SINTRACAP, 2017. 
El año 2008 el SINTRACAP recambia sus liderazgos sindicales, y tras un par de años de formación, articulación con las otras organizaciones de TCP de Chile, instancias de solidaridad y aprendizaje a nivel internacional, y sobre todo con el respaldo de un Convenio Internacional, se lanza en 2011 a pedirle al gobierno del entonces Presidente Sebastián Piñera una mesa de negociación para avanzar en sus demandas por la dignificación del trabajo de casa particular: "armadas del mencionado convenio y de la adherencia del Estado chileno a éste (debido a que el Gobierno votó su aprobación en la OIT en 2011), comenzamos el deambular en las esferas del poder para obtener la ratificación en nuestro país" 82. En paralelo, en los meses de junio y julio del 2011, dos comisiones de diputados de la República ingresan dos mociones parlamentarias ${ }^{83}$. La estrategia social-política de las TCP desde este momento hasta el año 2014 puede verse en el Esquema 2.

En el segundo año del primer mandato de Sebastián Piñera (2010-2013) ${ }^{84}$, en julio de 2011, se conforma una mesa de trabajo entre el ejecutivo y las organizaciones de trabajadoras de casa particular adheridas a la Coordinadora de TCP. De esa mesa de trabajo, diez meses después, en mayo de 2012, emergió la Iniciativa de Ley del ejecutivo que hizo discutir al parlamento:

(...) nuestro Gobierno (Piñera) recibió el relevante aporte de asociaciones de trabajadoras de casa particular representativas del sector, así como de la Oficina Subregional de Santiago de la Organización Internacional del Trabajo ${ }^{85}$.

Según comentan las trabajadoras del SINTRACAP86, el año 2011 se vieron obligadas a realizar una marcha para "presiona" al gobierno Piñera para que enviara a la Cámara de Diputados la iniciativa de Ley según lo negociado con las trabajadoras durante el año. Si bien la marcha tuvo una baja convocatoria (alrededor de 100 trabajadoras) esta parece haber conseguido sus objetivos: en mayo del 2012 Piñera envió la iniciativa del Ley al Congreso ${ }^{87}$.

En la mesa de trabajo del 2011 del gobierno de Piñera con las trabajadoras de casa particular se acordó avanzar en una propuesta de Ley que recogiera algunas de las quince demandas de la Coordinadora. Tras las negociaciones se decidió legislar por tres de estas demandas:

Igualación de la jornada laboral con la de cualquier trabajador en Chile; elaboración de un contrato tipo que contuviera información relevante y la especificación precisa del tipo de funciones y el lugar donde estas se realizarían; y, establecimientos de procesos claros de fiscalización y la definición de protocolos para el cumplimiento de dicha labor a la Dirección del Trabajo ${ }^{88}$.

El año 2013 la Coordinadora de Trabajadoras dirá a la Cámara de Diputados que el proyecto de Ley "solo se hace cargo de dos de las tres demandas cuyo avance se había prometido" 89 . El ejecutivo dejó de lado la decisión de ratificación del Convenio 189 de la OIT, no introdujo las demandas de las trabajadoras relativas a la formalización del empleo y a la especificación precisa del tipo de funciones y el

82 Ruth Olate, 2014.

83 Biblioteca del congreso nacional, 2015. Historia de la Ley 20.786

${ }^{84}$ Piñera ha gobernado en dos ocasiones el país, entre 2010 y 2013, y entre 2018-2021. Su gobierno se define como de "centro derecha" y se compone principalmente por los partidos Renovación Nacional (RN) y Unión Democrática Independiente (UDI). Bachelet, de quien se hablará más abajo, también ha gobernado el país en dos ocasiones, entre 2006-2009 y entre 2014 y 2017. Sus gobiernos se han definido como de "centro izquierda", estando el Partido Democracia Cristiana (PDC), Partido Socialista (PS) y Partido por la Democracia (PPD) en las bases de ambos gobiernos de Bachelet, y el Partido Comunista (PC) exclusivamente en las del segundo.

85 Biblioteca del congreso nacional, 2015. Historia de la Ley 20.786

${ }^{86}$ Cuaderno de Campo (2018).

87 Biblioteca del congreso nacional, 2015. Historia de la Ley 20.786

88 Biblioteca del congreso nacional, 2015. Historia de la Ley 20.786

${ }^{89}$ Biblioteca del congreso nacional, 2015. Historia de la Ley 20.786 
lugar donde estas se realizarían, como también garantizó insuficientes días de descanso para las trabajadoras puertas adentro: "Tuvimos que trabar al final, porque era un proyecto bastante precario, y lo logramos trabar y lo dejamos para este gobierno (El segundo de Michelle Bachelet)" ${ }^{90}$.

Entonces, el año 2011 fue el año de negociación y presión de la Coordinadora de Trabajadoras de casa particular con el gobierno de Piñera. El año 2012 fue el año de discusión de la propuesta del ejecutivo, y de las dos mociones parlamentarias mencionadas, en la Cámara de Diputados (agostoseptiembre). El año 2013 será el año en que discute el Parlamento la Iniciativa de Ley refundida con las mociones parlamentarias, donde las trabajadoras de casa particular frenarán la discusión parlamentaria del Senado, en tanto la normativa ingresada por el ejecutivo les parecía insuficiente.

Mientras la iniciativa de Ley se discutía en el Parlamento, tanto durante el gobierno de Piñera como durante el gobierno de Bachelet, las trabajadoras no estuvieron inmóviles, durante este tiempo fueron a exponer al Congreso e hicieron lobby con cada Diputado de la República:

Cuando íbamos al parlamento, íbamos oficina a oficina, dejamos cartas pidiendo el apoyo de cada diputado y senador, con la ministra, y así fuimos trabajando, Muchas veces fuimos a exponer al senado a decir porque nosotras queríamos tener una jornada laboral que el pleno siglo XXI estaba tan esclavizada, era una esclavitud moderna ${ }^{91}$

Específicamente, el ingreso de las trabajadoras de casa particular al Parlamento comenzó en marzo del 2013, cuando se junta por primera vez la Comisión de Trabajo de la Cámara de Diputados a discutir la iniciativa de Piñera y las otras dos parlamentarias. Desde esta primera instancia las trabajadoras ya comienzan a presentar sus críticas al proyecto ${ }^{92}$.

La siguiente Comisión (mixta) fue celebrada en julio de 2013, y en esta también participaron las dirigentes gremiales de las trabajadoras de casa particular. Así mismo, las críticas al proyecto continúan: "en los términos en que fue despachada por la Cámara de Diputados, no representaría un avance significativo en las condiciones de trabajo de los trabajadores del sector, toda vez que contendría una serie de falencias que es preciso subsanar"'93.

En 2013 todas las organizaciones de la Coordinadora de TCP concuerdan en que el proyecto de Ley es insuficiente. Luego de estas Comisiones las trabajadoras ya no participarán más “formalmente” de la discusión de la Ley hasta el año 2014, cuando se les vuelve a invitar al Parlamento a discutir la Iniciativa de Ley con modificaciones del nuevo ejecutivo. Tras el agotamiento de la discusión del Senado del insuficiente proyecto de Piñera, y frente a la pronta llegada de elecciones presidenciales en octubre de 2013, las trabajadoras redirigen su acción y diálogo hacia los candidatos presidenciales:

le entregamos a cada uno de los candidatos, que vinieron aquí a nuestro sindicato, le entregamos nuestro proyecto. Con esto nos comprometimos con la presidenta Michelle Bachelet. Ella dijo que si llegaba al gobierno se comprometía, iba a hacer efectivo tanto el proyecto que teníamos como el convenio 189 de la OIT. Así fue po"94.

Finalmente, la apuesta política de las trabajadoras ganó las elecciones. Bachelet asumiría el ejecutivo en marzo de 2014, y con eso, se avanzaría en las demandas de las trabajadoras. El año 2014 se volverá a discutir en comisiones del Senado el proyecto de Ley 20.786, esta vez con las indicaciones que el Gobierno de Michelle Bachelet incluiría. Como bien señala la dirigenta del SINTRACAP, este proyecto de Bachelet expresaba el espíritu de la Coordinadora de TCP en tanto este proyecto "no se escribió por

\footnotetext{
${ }^{90}$ Entrevista Dirigenta SINTRACAP, 2017.

${ }^{91}$ Entrevista Dirigenta SINTRACAP, 2017.

92 Biblioteca del congreso nacional, 2015. Historia de la Ley 20.786

93 Biblioteca del congreso nacional, 2015. Historia de la Ley 20.786

${ }^{94}$ Entrevista Dirigenta SINTRACAP, 2017.
} 
sí solo en el programa de gobierno, sino que fue resultado de las largas conversaciones y el lobby político realizado por las diversas dirigentas en las comisiones" ${ }^{25}$. Es más, según una de las socias de SINTRACAP 96 , la presión de las trabajadoras en las calles fue clave para que el ejecutivo se decidiera enviar el nuevo proyecto de Ley al Parlamento: en marzo de 2014, a días de recién haber asumido el gobierno de Bachelet, las trabajadoras realizan "novedosa" marcha y cacerolazo, que ocurrió en el "barrio alto" de Santiago ${ }^{97}$. En este acontecimiento las trabajadoras pidieron al gobierno la ratificación del Convenio 189 de la OIT y la mejora de la iniciativa de Ley presentada por Piñera en 2012, discutida por la Cámara de Diputados el mismo año y frenada por las trabajadoras después de su discusión en la Comisión de Trabajo del Senado el 201398.

Así, el 02 de julio de 2014 las organizaciones de TCP son nuevamente invitadas a las comisiones parlamentarias a expresar sus opiniones respecto a las nuevas indicaciones a la Ley -fruto de las negociaciones realizadas por la misma Coordinadora de TCP-. Esta vez todas las organizaciones de trabajadoras de casa particular expresaron su aprobación al proyecto. El SINTRACAP manifestó:

su conformidad con la indicación del Ejecutivo en lo relativo a la especificación, en el contrato de trabajo de los trabajadores de casa particular, de las labores que deben desempeñar, el domicilio de la prestación de servicios y la eventual obligación de asistencia a personas enfermas o niños ${ }^{99}$.

El SINDUCAP también dirá que el proyecto fue un avance: "la indicación del Ejecutivo resuelve adecuadamente dicha problemática, al establecer la aplicación de cuatro días adicionales de descanso dentro de cada mes calendario, adicionales al descanso semanal los días domingo"100.

Así, con el respaldo de las trabajadoras de casa particular a la iniciativa de Ley esta entra a la Cámara de Senadores para ser discutida y aprobada por la misma. En esta instancia las trabajadoras también se movilizarán para mostrar su respaldo a la Ley:

Nosotras, en el 2014, el 24 de setiembre, en Chile surgió un Congreso Internacional. Vinieron varios países, y justo ese día 24 se votó en el Senado la Ley. Y partimos todas: arrendamos dos micros y partimos al Congreso a Valparaíso. Y partimos para allá, todas con pancartas, con cuestiones ${ }^{101}$.

Dos semanas después, el 07 de octubre de 2014, la iniciativa vuelve a ingresar a la Cámara de Diputados para ser discutida con las modificaciones del nuevo ejecutivo. La iniciativa se aprueba por la Cámara y así se convierte en Ley a fines del mes de octubre. En esta instancia las trabajadoras también se movilizaron en las tribunas y, sobre todo, haciendo lobby con los senadores antes de comenzar la discusión: "Hoy en la mañana, varios diputados nos reunimos con los representantes de la Asociación Nacional de Trabajadores de Casas Particulares, quienes nos hicieron un llamado para apoyar este proyecto" 102 .

En estas últimas instancias de discusión parlamentaria (septiembre y octubre de 2014) dos cuestiones llaman la atención: (1) varios senadores y diputados visibilizan la importancia que tuvieron las organizaciones de TCP en la elaboración y aprobación de la Ley ${ }^{103}$, y (2) todos están a favor de la Ley, haciendo meas culpas por no haber legislado antes a favor de un gremio tan fundamental como las TCP

\footnotetext{
95 Ruth Olate, 2014.

${ }^{96}$ Cuaderno de Campo (2018).

97 OIT, 2014. La acción específicamente ocurrió en la comuna de las Condes, una de las comunas de más altos ingresos del país y donde trabaja la mayoría de las TCP de Chile (CASEN 2017).

98 OIT, 2014.

99 Biblioteca del congreso nacional, 2015. Historia de la Ley 20.786

100 Biblioteca del congreso nacional, 2015. Historia de la Ley 20.786

101 Grupo Focal SINTRACAP RM, 2017.

102 Diputado Sandoval, Historia de la Ley 20.786.

103 Biblioteca del congreso nacional, 2015. Historia de la Ley 20.786
} 
(Historia de la Ley 20.786): “Los senadores, ipero se acuchillaban! y decían: "pero ¡cómo puede ser, en pleno siglo XXI estén todavía las trabajadoras en esclavitud, que no tengan un contrato digno, que no tengan un sueldo digno!"104.

\section{Conclusiones}

A lo largo del presente artículo se ha mostrado que el proceso de organización sindical contra la precariedad laboral de las trabajadoras de casa particular fue exitoso, en tanto consiguió la aprobación de una legislación desprecarizante del trabajo doméstico. Esto fue posible, en un contexto de debilidad estructural del gremio de casa particular, a partir de tres estrategias sindicales: (1) establecimiento de alianzas con otras organizaciones y sindicatos del gremio, (2) movilización de la institucionalidad internacional para presionar al Estado chileno y (3) generación de alianzas, intercambios y algunas presiones hacia los actores políticos para que aprueben reformas a su favor.

La primera estrategia sindical se basó principalmente en la movilización del poder social ${ }^{105}$, específicamente mediante el establecimiento de alianzas y programas de acción conjuntos entre sindicatos, lo que les permitió a las organizaciones de trabajadoras de casa particular superar, durante el periodo 2010-2014, los efectos atomizantes del paralelismo sindical en el gremio. La segunda estrategia de SINTRACAP se basó en la movilización del poder institucional106, específicamente la movilización del derecho internacional, con el cual las trabajadoras presionaron al Estado de Chile, exigiendo una nueva institucionalidad laboral ajustada a los nuevos requerimientos de la Organización Internacional del Trabajo. La tercera estrategia de SINTRACAP también se basó principalmente en la movilización del poder social ${ }^{107}$, es decir, en el establecimiento de alianzas, intercambios y cooperaciones con actores sociales. Pero los actores de esta estrategia, a diferencia de los señalados por la literatura de los recursos de poder utilizada para realizar la presente investigación ${ }^{108}$, no eran movimientos sociales u otros sindicatos, sino que parlamentarios y gobiernos, por lo que este poder fue denominado como "socialpolítico". La consideración de este ámbito político de la acción sindical, la acción sindical "política"109, ha estado curiosamente ausente en los estudios sindicales de los últimos años en Chile, pese a que las relaciones entre sindicatos y partidos han sido unos de los elementos más estudiados del sindicalismo y del mundo del trabajo durante el siglo XX en América Latina ${ }^{110}$.

Continuar investigando las alianzas e intercambios de los actores sindicales con los actores de la política parece ser una temática de investigación necesaria, que alumbraría un aspecto de la realidad nacional hasta ahora poco visibilizado, que tiene que ver con las formas mediante las cuales el Estado se va construyendo y la institucionalidad laboral rehaciéndose, por la acción combinada de actores sindicales y políticos. Esta línea llevaría a retomar la primera ola del enfoque de los recursos de poder ${ }^{111}$, que tenía como principal pretensión entender la existencia de las formas de Estado del Bienestar de la posguerra y no así el éxito o fracaso de determinadas estrategias sindicales, como la segunda ola ${ }^{112}$. Desde esta

104 Grupo focal SINTRACAP RM, 2017.

105 Schmalz, op. cit.

106 Schmalz, op. cit.

107 Schmalz, op. cit.

108 Ludwig, Webster, y Schmalz, op. cit.; Schmalz, op. cit.

${ }_{109}$ Hamann y Kelly, op. cit.; Hyman y Gumbrell-McCormick, op. cit.

110 De la Garza, Enrique, ed. Los estudios laborales en América Latina: orígenes, desarrollo y perspectivas. Barcelona: Anthropos Editorial, 2016.

111 Korpi, Walter. «Power resources approach vs. action and conflict: on causal and intentional explanations in the study of power». Sociological Theory 3 (2): 31-45. (1985).

112 Ludwig, Webster, y Schmalz, op. cit.; Schmalz, op. cit. 
primera perspectiva, las luchas de las organizaciones de clase tendrían un rol protagónico en la producción del Estado, en tanto las instituciones sociales son vistas como residuos de activaciones previas de recursos de poder, a menudo en el contexto de conflictos manifiestos que por el momento se han resuelto a través de diversos tipos de compromisos ${ }^{113}$.

La movilización de los poderes sociales y políticos por parte de SINTRACAP no solo expresan y son fruto de una orientación sindical bastante evidente hacia la integración social ${ }^{114}$, sino que también expresa los poderes que SINTRACAP efectivamente tiene para movilizar dados sus bajos poderes estructurales y asociativos. Es decir, las estrategias sindicales utilizadas por SINTRACAP no solo expresan determinada ideología, nivel de conciencia o grado de politización, sino que también las posibilidades efectivas que tiene una organización sindical pequeña (debilidad asociativa) que agrupa a trabajadoras domésticas (debilidad estructural), las cuales trabajan de manera desconcentrada y descentralizada, tienen condiciones de empleo informales, tienen relaciones paternalistas con sus empleadores y tienen un bajo potencial disruptivo sobre la (re)producción.

Pese a que la Ley N²0.786 fue un avance para el gremio en tanto "desprecarizó" de forma importante el trabajo doméstico asalariado, varios parlamentarios y dirigentas de las trabajadoras expresaron la necesidad de avanzar en más cuestiones. En general estos actores piden limitar la jornada de las trabajadoras puertas adentro a ocho horas (como el resto de los trabajadores del país), disminuir la excesiva carga de posibles horas extra semanales que pueden realizar las trabajadoras (de 15 a 12 horas, también como el resto de los trabajadores del país), tener un seguro de cesantía, que el Estado se haga cargo de la deuda histórica que tiene hacia las trabajadoras de casa particular por permitir durante años que sus sueldos pudieran estar bajo el mínimo nacional, lo que generó que los empleadores les cotizaran por menos del sueldo mínimo y, sobre todo, fiscalizar el que efectivamente la relación de trabajo se formalice y se respeten las condiciones de trabajo y empleo que garantiza la Ley $\mathrm{N}^{\circ} 20.786$. Este último punto tiene que ver, entre otras cosas, con que todavía existe una alta proporción de trabajadoras y empleadores que se relacionan laboralmente de manera informal, pese a que la legislación obliga al empleador a registrar la relación de trabajo y cotizar a la seguridad social de las trabajadoras.

¿Qué pasó con estos elementos pendientes que perfeccionarían la Ley que alegaron algunos políticos y sobre todo las trabajadoras? Hasta ahora, inicios del 2019, no ha habido más modificaciones legales ni grandes discusiones políticas, salvo algunas mesas de negociaciones de demandas de ANECAP, SINDUCAP y SINTRACAP con las autoridades laborales del segundo gobierno de Piñera (20182021) $)^{115}$

Cuatro cuestiones parecen haber cambiado respecto al periodo 2010-2014, lo que puede explicar la ausencia de nuevas modificaciones institucionales por el efecto de la acción sindical de las organizaciones de trabajadoras de casa particular. La primera, es que la Coordinadora de trabajadoras de casa particular luego del 2014 casi no ha existido, las tres organizaciones que la constituían se han tendido a aislar, dificultando la consolidación de un petitorio unificado y claro en el gremio. La segunda, es que SINTRACAP le declaró su apoyo político al candidato Guillier (continuidad de Bachelet) a cambio de más reformas para el gremio, pero este candidato perdió, por lo que llegó al poder por segunda vez Piñera, con quien SINTRACAP no había establecido pactos previos y con quien la experiencia del 2010-2013 demostró que no se puede avanzar sustantivamente. La tercera, es que no han existido coyunturas de abuso hacia las trabajadoras de casa particular, o impactantes mediáticamente, lo que les ha impedido a las organizaciones de trabajadoras de casa particular mostrarse como victimas hacia la opinión pública,

Para una incipiente crítica a este enfoque véase Kenny, Bridget. «Labour Politics and South African Retail Workers: Enduring Collectivities in the Face of Precariousness». En Global Perspectives on Workers' and Labour Organizations, de Maurizio Atzeni y Immanuel Ness. Springer Singapore, 2018.

113 Korpi, op. cit.

114 Hyman, Richard. Understanding European trade unionism: between market, class and society. Sage, 2001.

115 Cuaderno de Campo, 2018. 
para así presionar por más reformas. La cuarta es que en el exitoso proceso de movilización política de 2010-2014 las organizaciones de trabajadoras de casa particular parecen haber descuidado a sus bases sindicales. En el caso de la FESINTRACAP cada sindicato parece haberse atomizado y, sobre todo, la afiliación y la participación sindical disminuir. Es decir, pese a las victorias políticas, SINTRACAP no logró crear poder asociativo en el proceso de organización estudiado.

Durante el periodo 2010-2014 el SINTRACAP parece haber basado su poder en recursos externos a su organización y a las posiciones que ocupan sus socias en la (re)producción y en el mercado de trabajo, lo que le impidió generar fuerza asociativa en su proceso de organización sindical. El problema de las fuentes de poder externas, como los recursos de poder institucionales, sociales-sindicales y socialespolíticos utilizados por SINTRACAP, es que no dependen de la sola voluntad y posición en la producción y el mercado de las trabajadoras, como el "poder asociativo" y el "poder estructural". El "poder social" y el "poder institucional" de los trabajadores y trabajadoras dependen sobre todo de los intereses y estrategias de otros actores sociales y políticos ("poder social"), y de la existencia de instituciones favorables a los trabajadores y trabajadoras ("poder institucional"). Ambas condiciones, actores e instituciones favorables a los intereses de una fracción de trabajadores y trabajadoras, son cuestiones que pueden cambiar repentinamente y dejar en un aprieto a las organizaciones sindicales ${ }^{116}$. Entonces, los recursos de poder sindicales no dependen de la pura voluntad y de las posiciones estructurales de los trabajadores y las trabajadoras, sino también y de manera importante de los intereses y estrategias de otros actores sociales y políticos. En el presente artículo se ha relacionado el poder social-político de SINTRACAP con los intereses de gobiernos y parlamentarios, jugando estos actores un rol de poder para SINTRACAP. Pero también, estos mismos actores políticos, o los empleadores en el caso de relaciones laborales "típicas", pueden desarrollar estrategias de "contra poder" para las organizaciones sindicales117. Para el caso de las trabajadoras de casa particular no existen actores empleadores colectivos que operen en oposición a los sindicatos de trabajadoras, pero en otras realidades laborales más cercanas al trabajo clásico estos actores existen y operan en los espacios políticos.

¿Es posible revertir este proceso de estancamiento sindical y de dependencia de fuentes de poder externas? El SINTRACAP parece haberlo demostrado en su historia, pero, aun así, nunca ha superado ciertos límites de afiliación y participación: ¿será posible revertir las determinantes estructurales que dificultan la sindicalización de las trabajadoras? Ante la carencia de poder asociativo y la dependencia de fuentes de poder externas, ¿Qué hacer con el nuevo gobierno de derecha? ¿serán posibles avances durante este gobierno para las trabajadoras de casa particular? Solo la historia que construya el gremio de trabajadoras de casa particular en Chile dará respuestas.

\section{Bibliografía}

Aravena, Antonio. «La recuperación de los estudios laborales en Chile (1990-2014)». En Los estudios laborales en América Latina, de Enrique De la Garza, 103-126, 2016.

Aravena, Antonio, y Daniel Núñez. El renacer de la buelga obrera en Chile: el movimiento sindical en la primera década del siglo XXI. Instituto de Ciencias Alejandro Lipschutz (ICAL), 2009.

Atzeni, Maurizio, y Immanuel Ness, eds. Global Perspectives on Workers' and Labour Organizations. Work, Organization, and Employment. Springer Singapore, 2018.

Bank, Carolina. Building Power from Below: Chilean Workers Take On Walmart. Cornell University Press, 2017. Boccardo, Giorgio, Carlos Ruiz, Rodrigo Cornejo, Andrés Bustamante, Ángel Martin, y Ignacio Becker. «Estudio Caracterización de Riesgos Psicosociales en Trabajadoras de Casa Particular», 2017.

Clark, Paul F. Building more effective unions. Cornell University Press, 2013.

116 Bank, op. cit., 142.

117 Ludwig, Webster, y Schmalz, op. cit. 
Coller, Xavier. Estudios de caso. Cuadernos metodológicos 30. Madrid, España. Centro de Investigaciones Sociológicas, 2000.

Darlington, Ralph. «Leadership and Union Militancy: The Case of the RMT». Capital \& Class 33, n. 3 (2009): 3-32.

De la Garza, Enrique. «Del concepto ampliado de trabajo al sujeto laboral ampliado». En Sindicatos y nuevos movimientos sociales en America Latina, de Enrique De la Garza. Buenos Aires: CLACSO, 2005.

De la Garza, Enrique, ed. Los estudios laborales en América Latina: origenes, desarrollo y perspectivas. Barcelona: Anthropos Editorial, 2016.

Del Campo, Andrea, y Soledad Ruiz. «Empoderamiento de Trabajadoras de Casa Particular Sindicalizadas». Psykhe (Santiago) 22, n. 1 (2013): 15-28.

Dirección del Trabajo. «ENCLA 2014. Informe de Resultados Octava Encuesta Laboral». Santiago, 2015. Dörre, Klaus, Hajo Holst, y Oliver Nachtwey. «Organising-A strategic option for trade union renewal?» International Journal of Action Research 5, n. 1 (2009): 33-67.

Federici, Silvia. El patriarcado del salario. Críticas feministas al marxismo. Traficante de Sueños, 2018.

Gálvez, Thelma, y Rosalba Todaro. «Trabajadoras de Casa Particulan. Círculo de Estudios de la Mujer (CEM), 1984.

Garretón, Manuel Antonio. Hacia una nueva era politica: estudio sobre las democratizaciones. Fondo de Cultura Económica, 1995.

Garretón, Manuel Antonio. Neoliberalismo corregido y progresismo limitado. Los gobiernos de la Concertación en Chile, 1990-2010, 2013.

Goldsmith, Mary. «Los espacios internacionales de la participación política de las trabajadoras remuneradas del hogan». Revista de Estudios Sociales, n. 45 (2013): 233-46.

Gutiérrez, Francisca. «Oportunidades y peligros del pluralismo sindical en el Chile post-transición». Nuevo Mundo Mundos Nuevos. Nouveaux mondes mondes nouveaux-Novo Mundo Mundos Novos-New world New worlds, 2013.

Hamann, Kerstin, y John Kelly. «Union Revitalization through Political Action? Evidence from Five Countries». En IRRA 55TH ANNUAL PROCEEDINGS, 2003.

Harvey, David. Diecisiete contradicciones y el fin del capitalismo. IAEN-Instituto de Altos Estudios Nacionales del Ecuador, 2014.

Hatton, Erin. «Mechanisms of Invisibility: Rethinking the Concept of Invisible Work». Work, Employment and Society 31, n. 2 (2017): 336-51.

Henríquez, Rodrigo. «Manipuladoras. Conflicto y acción sindical efectiva en trabajadoras del servicio de alimentación escolan». Santiago: Documentación, Publicaciones y Estadísticas. Dirección del Trabajo. Gobierno de Chile, 2017.

Hyman, Richard. Understanding European trade unionism: between market, class and society. Sage, 2001.

Hyman, Richard, y Rebecca Gumbrell-McCormick. «Trade unions, politics and parties: is a new configuration possible?» Transfer: European Review of Labour and Research 16, n. 3 (2010).

Jiang, Joyce. «Organizing Immigrant Workers Through 'Communities of Coping': An Analysis of Migrant Domestic Workers' Journey from an Individual Labour of Love to a Collective Labour with Rights». En Global Perspectives on Workers' and Labour Organizations, 23-42. Springer, 2018.

Julián, Dasten. «Precariedad laboral y repertorios sindicales en el neoliberalismo: Cambios en la politización del trabajo en Chile». Psicoperspectivas. Individuo y Sociedad 17, n. 1 (2018).

Kelly, John. Rethinking industrial relations: Mobilisation, collectivism and long waves. Routledge, 2012.

Kenny, Bridget. «Labour Politics and South African Retail Workers: Enduring Collectivities in the Face of Precariousness». En Global Perspectives on Workers' and Labour Organizations, de Maurizio Atzeni y Immanuel Ness. Springer Singapore, 2018.

Korpi, Walter. «Power resources approach vs. action and conflict: on causal and intentional explanations in the study of power». Sociological Theory 3 (2): 31-45. (1985). 
Lévesque, Christian, y Gregor Murray. «Understanding union power: resources and capabilities for renewing union capacity». Transfer: European Review of Labour and Research 16, n. 3 (2010): 333-350.

Ludwig, Carmen, Edward Webster, y Stefan Schmalz. «The Power Resources Approach: Developments and Challenges», 2018.

Manky, Omar. «Resource Mobilisation and Precarious Workers' Organisations: An Analysis of the Chilean Subcontracted Mineworkers' Unions». Work, Employment and Society 32, n. 3 (2018): 581-98.

Neilson, Brett, y Ned Rossiter. «Precarity as a Political Concept, or, Fordism as Exception». Theory, Culture \& Society 25, n. ${ }^{0}$ 7-8 (2008): 51-72.

OHL. «Informe de Huelgas Laborales 2016». Centro de Estudios del Conflicto y la Cohesión Social COES, 2017.

Piñeyro, Carlos. «Organización, emociones y resistencia de las trabajadoras del hogar latinas y caribeñas en la Ciudad de Nueva York, Estados Unidos». Revista Latinoamericana de Antropología del Trabajo 3 (2018). Quay Hutchison, Elizabeth. «Identidades y Alianzas: El movimiento chileno de las Trabajadoras de Casa Particular durante la Guerra Fria». Nuevo Mundo Mundos Nuevos. Nouveaux mondes mondes nouveaux - Novo Mundo Mundos Novos - New world New worlds, 2013.

Santibáñez, Camilo, y Frank Gaudichaud. «Los obreros portuarios y la idea de "posición estratégica” en la postdictadura chilena (2003-2014)». En Trabajadores y trabajadoras. América en movimiento, 2017.

Schmalz, Stefan. «Los recursos de poder para la transformación sindical». Nueva sociedad, n. 272 (2017): 19-41.

Silver, Beverly J. Fuerzas de trabajo: los movimientos obreros y la globalización desde 1870. Madrid: Ediciones AKAL, 2005.

SINTRACAP. Cuadernillo de antecedentes históricos de SINTRACAP. Área metropolitana. 22-8-89, 1989.

Stake, Robert E. Investigación con estudio de casos. Ediciones Morata, 1998.

Stillerman, Joel. «Explaining Strike Outcomes in Chile: Associational Power, Structural Power, and Spatial Strategies». Latin American Politics and Society 59, n. 1 (2017): 96-118.

Valdés, Ximena, Carmen Godoy, y Angie Mendoza. «Acción colectiva y resistencia: asalariadas agrícolas en Chile frente a la precarización laboral.» Revista Izquierdas 35 (2017): 167-98.

Valenzuela, María Elena, y Solange Sánchez. «Trabajo doméstico e identidad: Las trabajadoras domésticas remuneradas en Chile». En ¿Que significa el trabajo hoy?, de Ana Cárdenas, Felipe Link, y Joel Stillerman. Santiago: Catalonia, 2012.

Vennesson, Pascal. «Estudios de caso y seguimiento de procesos: teorías y prácticas». En Enfoques y metodologías de las ciencias sociales: una perspectiva pluralista, 237-254. Akal, 2013.

Womack, John. «Posición estratégica y fuerza obrera». Hacia una nueva historia de los movimientos obreros. FCE, México, 2007.

Wright, Erik Olin. «Working-class power, capitalist-class interests, and class compromise». American Journal of Sociology 105, n. 4 (2000): 957-1002.

\section{Documentos analizados}

- Biblioteca Congreso Nacional (2014). Historia de la Ley N²0.786. Modifica la jornada, descanso y composición de la remuneración de los trabajadores de casa particular, y prohíbe la exigencia de uniforme en lugares públicos

- Contrato de trabajo TCP (2015) Contrato de trabajo Trabajadora de Casa Particular Puertas Afuera, Puertas Adentro y Parcial (vigencia desde el 01.01.2015)

- Ley 20.786 (2014). Modifica la jornada, descanso y composición de la remuneración de los trabajadores de casa particular, y prohíbe la exigencia de uniforme en lugares públicos

- Convenio 189 OIT (2011) Convenio sobre el trabajo decente para las trabajadoras y los trabajadores domésticos. 
- SINTRACAP (1989) Cuadernillo de antecedentes históricos de SINTRACAP. Área metropolitana. 22-8-89

- SINTRACAP (2003) Estatutos sindicales SINTRACAP (2003)

- Bases Licitación (2018) Bases Licitación Reconstrucción de Memoria Sindical SINTRACAP (2018).

\section{Medios de prensa analizados}

- La Cuarta (2018) Ruth Olate ahora lucha contra el cáncer de mamas y huesos

- Biobío Chile (2011) Sindicato Unitario de Trabajadoras de casa particular marchó por mejoras laborales

- El Ciudadano (2011) Primera marcha de nanas marca inicio de demandas laborales

- Radio Universidad de Chile (2011) Trabajadoras de condominio de Chicureo llegan a tribunales por discriminación

- Ruth Olate (2014) Trabajadoras de casa particular: del ninguneo a la acción sindical. Columna en El Mostrador.

- OIT (2014) Trabajadoras domésticas marchan para demandar ratificación del Convenio 189 en Chile

- La Tercera (2018) Ruth Olate: "No creo que me vaya a mejorar del cáncer; sólo pido no empeorar"

- La Tercera (2017) Los patrocinantes de la candidatura de Guillier: Desde el coach de las "marcianitas" hasta la dirigenta de las trabajadoras de casa particular

- Orellana (2018). “Aquí estamos, Pinochet”: La historia del primer \#8M en dictadura.

\section{Información producida y analizada}

- Entrevista Dirigenta SINTRACAP (2018).

- Grupo focal SINTRACAP RM (2017). Dirigentes y socias de la organización.

- Cuaderno de campo (2017) Observación no participante como investigador.

- Cuaderno de campo (2018-2019). Observación participante como asesor del sindicato.

- Entrevista Rosa. Santiago. Sindicalizada

- Entrevista Viviana. Santiago. Sindicalizada

- Entrevista Silvia. Santiago. Sindicalizada

- Entrevista Flor. Puerto Montt. No sindicalizada

- Entrevista Rosa. Puerto Montt. No sindicalizada

- Entrevista Gabriela. Ensenada. No sindicalizada

- Entrevista Paola. Santiago. No sindicalizada

- Entrevista Viviana. Puerto Montt. No sindicalizada

- Entrevista Jenny. Santiago. Sindicalizada

- Entrevista Eliana. Puerto Montt. No sindicalizada

- Entrevista Cecilia. Puerto Varas. No Sindicalizada 